\begin{tabular}{|c|c|c|c|c|c|c|c|c|c|}
\hline & \multirow{2}{*}{\multicolumn{2}{|c|}{$\begin{array}{l}\text { Per cent. of Zinc by } \\
\text { Gravimetric method } \\
\text { I II }\end{array}$}} & \multicolumn{4}{|c|}{$\begin{array}{l}\text { Per cent. of Zinc by Fer- } \\
\text { rocyanide method }\end{array}$} & \multirow[b]{2}{*}{ Average } \\
\hline & & & & & I & II & III & IV & \\
\hline \multicolumn{3}{|c|}{ 9. Silicate } & 39.25 & 39.24 & $40 . \infty 0$ & 40.00 & 40.00 & 40.00 & 40.00 \\
\hline \multicolumn{3}{|c|}{ 10. Carbonate } & 53.45 & 53.49 & 54.15 & 54.18 & 54.33 & $54 \cdot 35$ & 54.25 \\
\hline \multicolumn{10}{|c|}{ II. Sulphides with } \\
\hline \multicolumn{3}{|c|}{$\mathrm{Fe}, \mathrm{Mn}, \mathrm{Pb}$ and $\mathrm{Cu}$} & 43.12 & 43.01 & 43.50 & 43.62 & $43 \cdot 35$ & $43 \cdot 52$ & 43.49 \\
\hline 12. & “" & " & 29.78 & 29.65 & 30.00 & 30.08 & 29.92 & 29.72 & 29.93 \\
\hline $\mathrm{I}_{3}$. & $"$ & “ & 22. IO & 21.67 & 22.56 & $22.5^{6}$ & 22.56 & $22.6_{5}$ & $22.5^{8}$ \\
\hline I4. & “ & “" & 37.84 & $37 \cdot 53$ & $3^{8.24}$ & $3^{8.36}$ & $3^{8.48}$ & 38.86 & 38.48 \\
\hline$I_{5}$ & “ & “ & 41.62 & 4 ז. 75 & 42.60 & 42.80 & 42.40 & 42.20 & 42.50 \\
\hline I6. & 4 & “ & 42.28 & 42.00 & 43.20 & 43.40 & 43.28 & 43.20 & 43.27 \\
\hline 17. & $" 6$ & “ & $3^{8.76}$ & $3^{8.9} \cdot \mathrm{r}$ & 39.20 & 39.25 & $39 \cdot 32$ & 39.20 & 39.40 \\
\hline IS. & $"$ & " and & & & & & & & \\
\hline & As. & and $\mathrm{Ag}$ & 14.49 & I5.34 & I5.48 & 15.52 & I 5.43 & I5.45 & 15.47 \\
\hline 19. & $"$ & “ & 6.35 & 6.43 & 6.32 & 6.59 & 6.50 & 6.48 & 6.47 \\
\hline 20. & " & " & I 3.95 & $\mathrm{I} 4.2 \mathrm{I}$ & I 4.20 & 14.22 & I 4.22 & 14.27 & 14.23 \\
\hline
\end{tabular}

As is generally known, the gravimetric method for the determination of zinc gives low results. I give them to call attention to the differences in results likely to occur by different assayers using the two methods. In technical work the conditions under which the chemist works will generally cause loss of zinc in considerable quantity. It is my opinion that the results for zinc by the ferrocyanide method obtained by technical chemists more nearly approach the absolute amount of zinc in an ore sample than the results of chemists, working slowly, with the gravimetric method.

Chifuahta, Mexico.

[CONTRIBUTION FROM THE CONTRACTS LABORATORY, BUREAU OF ChEMISTRY PUBLISHED BY PERMISSION OF THE SECRETARY OF AGRICULTURE.]

\title{
THE DETERMINATION OF ZINC PRESENT AS CARBONATE AND SILICATE IN ORES
}

BY PERCY H. WALKER AND HERMAN SCHREIBER.

Zinc carbonate ores are more easily reduced than zinc silicate ores, and the former should be more valuable for the same zinc content. It is of some interest, therefore, to determine the relative proportion of zinc carbonate and zinc silicate present in a given ore. This problem presents a number of difficulties. It will not do to determine the carbon dioxide and from it calculate the zinc as carbonate, for the presence of other carbonates even in small amounts would cause absolutely false results. Equally as objectionable would be to determine the silica and calculate to zinc silicate.

Minor ${ }^{1}$ suggests determining total zinc in one portion and extracting the zinc carbonate from another portion by boiling 15 minutes with

${ }^{1}$ Chem. Ztg. 13, I670-Classen's Ausgewählte Methoden der Analytischen Chemie-Vol. I, page 352 . 
5o per cent acetic acid. This method is worthless, for zinc silicate is rapidly attacked by acetic acid even when dilute. A number of experiments with different acids were tried and we were unable to dissolve zinc carbonate in acid without at the same time dissolving a large proportion of the zinc present as silicate.

A more promising method which was suggested to us in a private communication by Thos. B. Johnson is to make a determination of total zinc and also of total silica and insoluble matter; another portion is treated with hydrochloric acid to decomposition but not evaporated to dehydrate silica. The solution is filtered, the residue washed with water, and then with hot potassium hydroxide solution, finally with water, ignited and weighed. The difference between the total insoluble and this insoluble in acid and alkali is taken as silica in combination as zinc silicate. This method, however, is also open to many objections. The assumption that zinc silicate is the only silicate present that forms a jelly with hydrochloric acid while of course open to objections as a general proposition may with most ores be made with small chance of error. The assumption, however, that only gelatinous silica is dissolved by hot alkali cannot be so easily accepted.

In order to test the separation we secured a sample of calamine free of carbonate and a sample of smithsonite containing no zinc silicate. The calamine was quite pure, but the snithsonite was not so good a sample, containing other carbonates, making a determination of total carbon dioxide useless. Insoluble siliceous matter and zinc were carefully determined in each of these and by mixing in definite proportions mixed material of known composition was secured for trying out the methods.

The prepared mixture contained a total of II.I 7 per cent. of insoluble siliceous matter, 17.29 per cent. zinc as silicate and 7.27 per cent. zinc as carbonate, a total zinc content of 24.56 per cent.

By decomposing this mixture with hydrochloric acid, filtering without dehydrating the silica, washing with water, caustic alkali, acid and water, I.00 per cent. of insoluble matter was obtained which gives I0.1 7 per cent. soluble silica. Calamine has a composition represented by the formula $\mathrm{H}_{2} \mathrm{Zn}_{2} \mathrm{SiO}_{5}$. The ratio of silica to zinc is $\mathrm{I}$ : 2.I7. By multiplying the soluble silica by 2.17 we get 22.07 per cent. zinc as silicate, an error of 4.78 per cent.

Another portion was treated in the same manner with the exception that the siliceous matter was washed with a 5 per cent. solution of sodium carbonate instead of caustic alkali. This also gave one per cent. insoluble. These experiments were considered conclusive as proving that we cannot wash silica with even carbonated alkali and avoid dissolving much more silica than that present as zinc silicate.

It is well-known that if calamine is treated with dilute hydrochloric 
acid it goes into solution before gelatinization sets in. Duplicate portions of 0.5 gram each of the mixed ore were treated with $5 \mathrm{cc}$ of water, Io cc hydrochloric acid, heated, filtered at once and washed with water alone. 3.74 per cent. and 3.54 per cent. insoluble matter was found, making 7.43 percent. and 7.63 per cent soluble silica, corresponding to 16. I 2 per cent and 16.56 per cent zinc as silicate, or an average of 16.34 per cent. The error in this case is -0.95 per cent.

This method gives much better results than the method of washing with alkali, but still gives results which can only be taken as a very rough approximation and in no sense as an exact determination.

Zinc carbonate is broken up at a lower temperature than any of the carbonates likely to occur in ores and it was thought that a method might be based on this property. A glass tube was fitted into an air bath carrying a thermometer. The mixed ore weighed in a porcelain boat was introduced into the tube, connected with the necessary air purifying and carbon dioxide absorption apparatus and the air bath then heated to a temperature between $350^{\circ}$ and $400^{\circ}$ for 45 minutes. The mixed ore by this process gave 4.21 per cent, 4.45 per cent and 4.30 per cent carbon dioxide. Smithsonite has the composition represented by the formula $\mathrm{ZnCO}_{3}$, the ratio of zinc to carbon dioxide being I: I.49 The zinc from the carbonate determinations therefore would be 6.27 per cent, 6.63 per cent and $6.4 \mathrm{I}$ per cent, an average of 6.44 per cent. The error here is -0.93 per cent. In order to test whether the low results here were due to incomplete decomposition of the zinc carbonate, at tempts were made to prepare pure zinc carbonate. These attempts were not successful, the product being basic in every case. A product was obtained, however, which contained no other metal and the carbon dioxide was determined in it by action of acid and by heating as in the case of the ore. The results obtained were: by acid I3.76-I3.83-I4.II$14.49-13.58$, average 13.95 per cent. By heat I3.91-I4.20-13.8113.79, average 13.92 per cent. The two ores were then separately treated by the acid method with the following results:

\begin{tabular}{|c|c|c|}
\hline & $\begin{array}{l}\text { Calamine } \\
26.92 \text { ) }\end{array}$ & $\begin{array}{c}\text { Smithsonite } \\
3.28)\end{array}$ \\
\hline Total insoluble siliceous matter........ & $26.84\}^{26.8}$ & $3.36\}$ \\
\hline Insoluble in acid without evaporating... & $\left.\begin{array}{l}2.60 \\
2.60\end{array}\right\} 2.60$ & $\left.\begin{array}{l}3.2 \mathrm{I} \\
3.28\end{array}\right\} 3.25$ \\
\hline
\end{tabular}

In the case of the calamine the soluble silica 24.28 per cent corresponds to 52.69 per cent zinc as silicate.

Zinc determinations gave

$$
\begin{aligned}
& 52.02-5 \mathrm{I} .9 \mathrm{I}-5 \mathrm{I} .8 \mathrm{I}-5 \mathrm{I} .72, \\
& \text { average } 5 \mathrm{I} .87 \text { per cent. }
\end{aligned}
$$


In the case of the carbonate the total siliceous matter and the insoluble in acid are practically the same. Hence the zinc may all be taken as carbonate.

In order to test the effect of the presence of other carbonates on the determination of zinc as carbonate, 0.5675 gram magnesite was mixed with 0.8780 gram of smithsonite and the carbon dioxide determined by heating and calculated to the smithsonite. This gave 6.83 per cent. while the smithsonite when heated alone gave 6.7 I per cent., 6.82 per cent. and $6.5 \mathrm{I}$ per cent. We are safe then in assuming that the presence of magnesite, one of the most easily decomposed carbonates, introduces little or no error.

It will be noticed that by the determination of zinc as silicate and zinc as carbonate in each case the results are low. Estimating the other form in each case by difference from total zinc, we have the following results :

Zinc as silicate determined.. 16.34

Zinc as carbonate by dif.... 8.22

Total ......... $\overline{24.56}$ by difference............. 8 . I 2

determined $\ldots \ldots \ldots \ldots \ldots \ldots, 6.44$

Total ........... 24.56

By taking the average of the two results in each case we get the following :

Zinc as silicate...................... 7.23

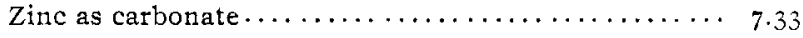

which results agree very well indeed with the amounts taken. This close agreement must, however, be due to considerable extent to accident and probably with other mixtures would not be so close.

Two ores containing both the carbonate and silicate were treated by the two processes with the following results :

\begin{tabular}{|c|c|}
\hline Number..................... ${ }_{2848}$ & C 2849 \\
\hline Total Zinc................. 39.04 & 28.10 \\
\hline Zinc as Carbonate determined....... & 24.18 \\
\hline Zinc as Carbonate by difference.... & 22.96 \\
\hline Zinc as Silicate determined...... 32.55 & 5.14 \\
\hline Zinc as Silicate by difference...... $33.3^{8}$ & 3.92 \\
\hline
\end{tabular}

From the work on a known mixture it would appear that the direct determination in each case leads to low results. That this assumption cannot be made in all cases, however, is evident when we examine the results on ore No. C 2849 where the sum of two forms of zinc determined is 29.32 per cent. while the total zinc determined is only 28. I0. At best one must be content with results which are ouly approximate, but by a combination of the two methods, the amounts of the two forms of zinc may generally be approximated with an error of probably not more than 3 or 4 per cent. 